\title{
Minining
}

http://dx.doi.org/10.1590/0370-44672018720093

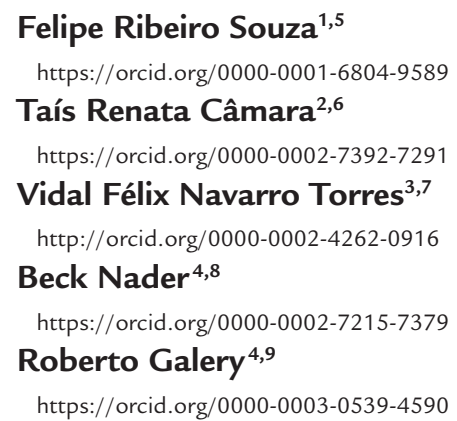

E-mails: ${ }^{5}$ felipe.souza@ufop.edu.br, 6taiscamara@gmail.com / tais.camara@vale.com, 7vidal.torres@itv.org / navarro.cvl@sapo.pt, beckn@demin.ufmg.br / beckn@usp.br, 'rgalery@demin.ufmg.br

\section{Optimum mine production rate based on price uncertainty}

\begin{abstract}
The production rate of a mining operation has an important effect on the operational cycle and gross profit, which are often evaluated based on engineering practices. Assessment of the economic performance of mine operations in mining engineering is of great importance because an incorrect production rate can result in significant financial losses. The production rate is composed of two bases: the cost estimation and the price scenario. Bureau of Mines studies performed on American mines indicated that processing costs can be estimated through the production rate. This article proposes to connect the model presented by the Bureau of Mines and queuing theory to describe the operational costs, which are used to develop a production optimization methodology. The proposed cost composition describes a production system to verify the law of diminishing returns and the economy of scale. Between these regions of the production curve, the optimum point was determined with mathematical precision.
\end{abstract}

keywords: production rate, marginal profit, mine optimization, elasticity, price simulation.

\section{Introduction}

Mining costs are generally high, both in the development and operational phases; therefore, it is important to use robust data for estimates. Another important consideration for an accurate cost estimation is the production rate, which must be defined before the beginning of operations and should be recalculated whenever necessary. The optimum production rate follows changes in sales price and costs and is influenced by market demand (Runge, 1998) and several factors related to the operation. Strategic mine planning should be periodically rebuilt to adapt to new possible market scenarios, follow the commodity price fluctuation and, if necessary, change the production rate over the mine life.

Taylor's rule has been used to estimate the mine production rate based mainly on the expected total reserve, but this rule has several gaps that do not consider operational and financial parameters in the estimation. Taylor (Taylor, 1986) showed that the empirical formulation was based on a study that analysed 30 projects. From Taylor's rule, the US Bureau of Mines (USBM) (Camm, 1991) performed a more detailed analysis using regression techniques that included the capital and operating costs of the formulation.

Sabour (Abdel Sabour, 2002) presented a review of the various methods for proposing the correct production rate. Dowd (Dowd, 1976) addressed the issue through dynamic programming with the premise that both costs and prices could be predicted accurately. Lizotte and Elbrond (Lizotte; Elbrond, 1982) reviewed this theory, demonstrating that there are fundamental differences between the dynamic programming model and the real processes. Wells (Wells, 1978) proposed a methodology for the optimization of 
the production rate based on the maximization of the present value ratio (PVR), that is, seeking the greatest relationship between the positive present value of the cash flow divided by the negative present value of the cash flow.

Cavender (Cavender, 1992) proposed a theory to find the optimum production rate through the net present value (NPV) optimization considering cash flow, stochastic modelling and prices. However, since this model was not composed of real operation constraints, it has not been widely applied. Smith (Smith, 1999) apud (Abdel Sabour, 2002) proposed an optimum range for the production rates with the highest value being the NPV maximum value point, and the lowest value was determined by the point at which the cash flow is the most efficient at repaying twice the capital cost.

Abdel Sabour (Abdel Sabour, 2002) developed a model based on marginal analysis, assuming that the production rate is optimized when the current marginal cost value is equal to the present value of the marginal revenue. Kizilkale and Dimitrakopoulos (Kizilkale; Dimitrakopoulos, 2014) presented a dynamic programming structure to estimate the optimum production rate under financial uncertainty. Their methodology was performed using a nonlinear formulation since complex mining systems can be modelled by linear equations. Their article presented an interactive and nonlinear formulation to account for the decrease

\section{Materials and methods}

\subsection{Marginal profit}

The marginal profit can be defined as the difference between the marginal revenue and the marginal cost. To optimize the profitability, the production must be adjusted to the point where the marginal profit is zero, which corresponds to the optimal production point. After this point, the increase in production will not contribute to an increase in the profit, since the production costs will also increase due to the diseconomy of scale.

The economy of scale is a strategy of large ore tonnage production at a low unit cost. Large equipment pres- in the reserve with each new period of operation. Mariz (2018) proved a correlation between the commodity and the equation used to represent the behavior. Each commodity present similar mining method, equipment, processing and revenue developing a similar behavior of the regression equation.

The main purpose of this study is to determine a mathematical formulation to optimize the mine production rate to achieve the maximum profit based on costs and revenues, as well as the methodology proposed by Abdel Sabour (Abdel Sabour, 2002). However, the main difference in the present approach is problem modelling, since the formulation of Abdel Sabour cannot correlate the production costs with the extraction rate.

The methodology considers the processing and mining costs individually to quantify the total cost. The processing cost is defined by the sum of the individual costs of each operation, such as crushing, sizing and concentration (Franco-Sepulveda; Campuzano; Pineda, 2017). For mining costs, the definition is based on the sum of unit operations such as drilling, blasting, and hauling.

Queuing theory is the mathematical study of waiting lines. This theory is modelled using two events: arrival and service (Kappas; Yegulalp, 1991). According to (Gross et al., 2008), a queuing system is one in which customers arrive for service, wait for service if it is not immediately available, and move on to the next server once they have been serviced. Usually, the arrival is modelled by the average rate of clients in the system, and the service is determined by the average number of visits performed per time interval (Chwif; Medina, 2007). Kappas and Yegulap (1991) developed a methodology to model the behaviour of the productive cycle of mining using their previous knowledge of the service and arrival models. Because the system exhibits Markovian behavior, linearly chained events, the classic formulations present in (Chwif; Medina, 2007), are used to determine the ideal quantity of equipment for the productive cycle.

Based on the concept of marginal revenue developed by the economic engineering theory, the proposed formulation determines how much an extracted unity increases the profit. The result is an increase in the productive capacity as revenue grows (Rendu, 2014). An increase in plant production leads to a decrease in the cost of ore production due to the economy of scale (Runge, 1998); the same approach can be applied to the mining cost. This study presents a formulation adaptable to each operation, and this formulation can provide a production rate according to financial changes. In scenarios regarding price reductions or increments, the production rate is adjusted to reach the maximum marginal profit. One hundred simulated scenario prices, representing 10 years of operation, were developed through geometric Brownian motion to determine the most likely production scenario. ents a high acquisition cost with a low operational cost. Low operating costs and high production capacities are the basis of economies of scale. Burgarelli et al. (Burgarelli et al., 2018) analysed the impact of the price on extremely sensitive iron ore deposit and cut off grade policy behavior showed that a change in ore price altered the destination can reach $45 \%$ of the scheduled blocks due the deposit behavior. This change can affect the haul distance and the mine cost.

A concept that can be applied to analyze the relationship between the ore production and sale price is the elasticity, which is defined as the ratio of the percentage change in a dependent variable to the variation in an independent variable. The price elasticity influences the production rate and company policy. For the case study, the elasticity shows the production reaction (Q) if price $(P)$ increases or decreases (Tcha and Wright, 1999; Hildenbrand, 2014). Equation 1 summarizes the concept of elasticity by presenting the ratio between the percentage variation in the price and the percentage variation in the quantity produced.

$$
\mathrm{e}=\frac{\frac{\Delta P}{P}}{\frac{\Delta Q}{Q}}
$$


Figure 1 shows a production increase when the elasticity(e) is greater than 1 , and the price reduction provides an increase in the demand and conse-

Figure 1

Profit elasticity.

Utility is used in decision theory to represent the positive result obtained by following a particular course of action. It is important to understand the correlation between profit and production developed by Rendu (Rendu, 2014), which determines the function to calculate profit based quently an increase in the profit. This analysis can also be conducted when the elasticity is less than 1 , demonstrating that an increase in production is insuf-

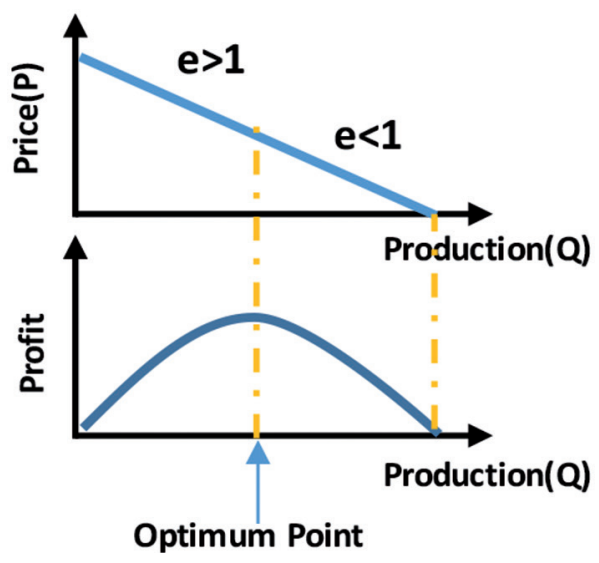

on the Lane formulation (Lane, 1988). Both authors are based on the theory of the firm (Coase, 1937) that defines profit as the difference between the revenue and cost. The revenue is a function of the total metal contained in the ore, and the costs are determined according to total material ficient to overcome the price decline. Marginal profit is related to a financial benefit increase with a production level change (Camus, 2002).

$$
U\left(T_{c^{+}}\right)=Q_{c^{+}} \cdot r\left(T_{c^{+}}\right) \cdot a / c \cdot V-T_{c^{+}} \cdot P_{o}\left(T_{c^{+}}\right)
$$

where: $\mathrm{V}=$ Ore value (US\$);

$\mathrm{T}_{\mathrm{ct}}=$ Tonnage above the cut-off (ton);

$\mathrm{Q}_{c+}=$ Quantity of ore processed in one year (ton);

The optimum plant capacity is reached when the maximum value equals $\mathrm{a}=$ Feed grade $(\%)$;

$\mathrm{c}=$ Concentrated grade $(\%)$;

$\mathrm{U}\left(\mathrm{T}_{\mathrm{c}^{+}}\right)=$Utility of the plant activity

at $\mathrm{T}_{\mathrm{c}^{+}}$capacity (US\$/ ton);

the value of the first derivative of utility, which is equal to zero (Equation 3). moved. To determine the costs, the process must be divided into two stages: first, the mine operation rates are fixed; next, the process operation rates are fixed. For an iron ore operation, the utility function considering the fixed mine operation rates can be expressed as (Equation 2):

$$
\frac{d U\left(T_{c^{+}}\right)}{d T_{c^{+}}}=0
$$

Applying the concept of Equation 2 to Equation 1, the following relation is obtained.

$$
\frac{d U\left(T_{c^{+}}\right)}{d T_{c^{+}}}=\frac{d Q_{c^{+}}}{d T_{c^{+}}} \cdot r\left(T_{c^{+}}\right) \cdot a / c \cdot V-P_{0}\left(T_{c^{+}}\right)+Q_{c^{+}} \frac{d r\left(T_{c^{+}}\right)}{d T_{c^{+}}} \cdot V-T_{c^{+}} \cdot \frac{d P_{0}\left(T_{c^{+}}\right)}{d T_{c^{+}}}
$$

Considering a minor change in the cut-off grade, the amount of material processed will be changed. Equation 5 presents the metal contained in ore, and Equation 6 shows the increase in the contained metal due the tonnage growth, where $X_{c^{+}}$corresponds to the average grade above the cut-off grade. The total amount of metal will contribute to the utility according to Equation 7.

$$
\begin{gathered}
Q_{c^{+}}=T_{c^{+}} \cdot X_{c^{+}} \\
Q_{c^{+}}+d Q_{c^{+}}=T_{c^{+}} \cdot X_{c^{+}}+d T_{c^{+}}, X_{c^{+}}
\end{gathered}
$$

Joining (6) and (4):

$$
U\left(T_{c^{+}}\right)=X_{c} \cdot r\left(T_{c^{+}}\right) \cdot a / c \cdot V-P_{0}\left(T_{c^{+}}\right)+Q_{c^{+}} \cdot \frac{d r\left(T_{c^{+}}\right)}{d T_{c^{+}}} \cdot V-T_{c^{+}} \cdot \frac{d P_{0}\left(T_{c^{+}}\right)}{d T_{c^{+}}}
$$


To determine the recovery equation and processing costs, the utility must be considered according to the production rate. The methodology developed by
Rendu (Rendu, 2014) was adjusted using parameters from a hypothetical iron ore deposit (Equation 8) to determine the relationship between the production rate and recovery, $r\left(T_{c^{+}}\right)$. Ideally, this function should be determined through tests in a pilot plant so that the values will be more definitive.

\subsection{Processing cost}

The second step relates the costs to the process route. In the Bureau of Mines cost estimating system handbook (Camm, 1991), there are several equations to estimate the processing cost of each step according to the quantity of ore processed

Milling cost:

$$
r\left(T_{c^{+}}\right)=-0.000006 x^{2}-0.021 x+0.9328
$$

by the plant (feed rate, $X_{d}$ ). A factor was applied based on the inflation rate available in the Institute Index Mundi; this factor aims to correct the values for the current conditions. Three operations were considered to estimate the processing costs:

milling (Equations 9, 10 and 11), impact crushing (Equations 12, 13 and 14) and flotation (Equations 15, 16 and 17). These 3 steps were adopted to simplify the process because they have greater operating costs in the iron ore projects.

Impact crushing:

$$
\begin{aligned}
& C_{\text {lab }}=17126\left(X_{d}\right)^{0.585} \\
& C_{\text {Sup }}=0.649\left(X_{d}\right)^{0.843} \\
& C_{\text {Rep }}=8.460\left(X_{d}\right)^{0.581}
\end{aligned}
$$

Flotation:

$$
\begin{gathered}
C_{\text {lab }}=483344+0.26 X_{d} \\
C_{\text {Sup }}=0.832\left(X_{d}\right) \\
C_{\text {Rep }}=4.13+0.149\left(X_{d}\right)^{0.013}
\end{gathered}
$$

where: $\mathrm{C}_{\text {lab }}=$ Labour cost (US\$/ ton);

$\mathrm{C}_{\text {sup }}=$ Energy supply cost (US\$/ ton); and

Considering Equations 9 to 17, Figure 2 shows the results of the to-

tal costs for each production rate. As expected, the processing cost decreases

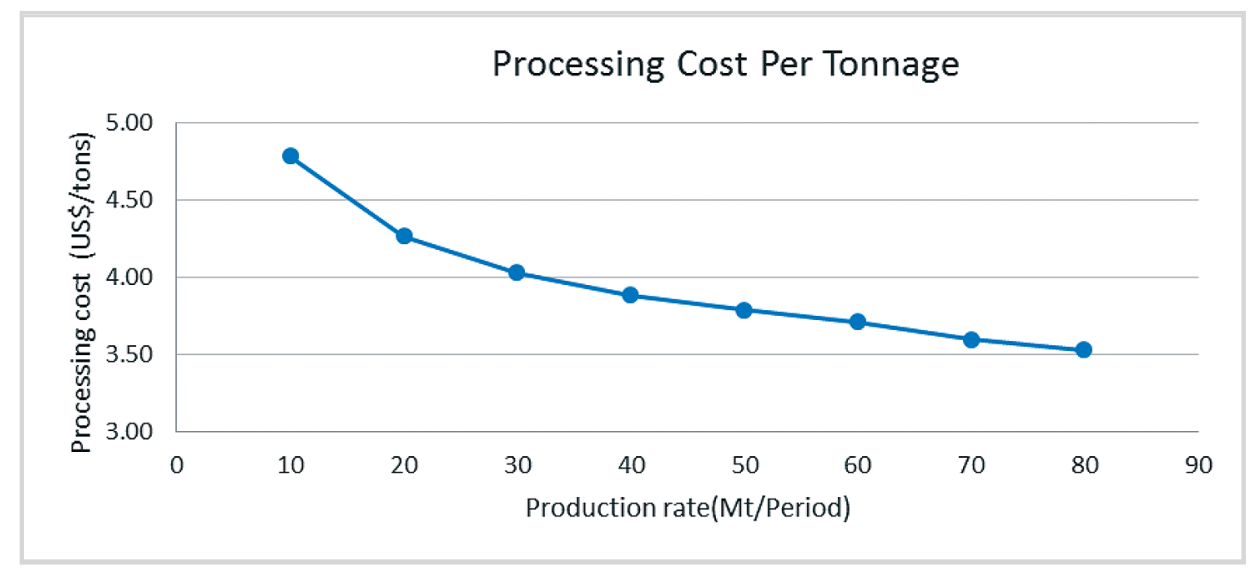

\subsection{Mining Cost}

To determine the utility function used in the optimization, it is important to

consider that processing costs are constant and that the mining costs are variable.
Figure 2

Processing cost according to the production rate.

Equation 18 shows the utility function of extraction considering processing cost as 
a constant variable. Equation 18 shows

$$
U\left(T_{c^{+}}\right)=Q_{c^{+}} \cdot r\left(T_{c^{+}}\right) \cdot a / c \cdot V-T_{c^{+}} \cdot P_{m 0}\left(T_{c^{+}}\right)
$$

The variability in the mining cost as a function of the independent variable tonnage will be based on queuing theory (Kappas; Yegulalp, 1991), since a mining

$$
P_{m 0}\left(T_{c^{+}}\right)=Q_{F r} \cdot N_{s}\left(T_{c^{+}}\right) \cdot\left(D_{c}\left(T_{c^{+}}\right)+E_{r}\right)
$$

operation composed of a truck and an excavator is perfectly modelled by this theory. Regarding mining operations, the attendant is represented by the loading equipment, and the truck represents an individual in the queue. The cost to load and transport the ore above the cut-off grade can be calculated according to Equation 19. where: $\mathrm{Q}_{\mathrm{Fr}}=$ Quantity of mining progress; $\mathrm{N}_{\mathrm{s}}=$ Number of trucks;

The arrival rate $(\lambda)$ of the hauling equipment (Equation 20) was calculated as a function of cycle times $\left(t_{c}\right)$ of
$\mathrm{D}_{c}=$ Diesel cost (US\$/ton);

$\mathrm{E}_{\mathrm{r}}=$ Equipment repair (US\$/ton);

the Markovian systems for excavators and trucks (Chwif; Medina, 2007). The arrival rate was used to determine

$$
\begin{gathered}
\lambda=\frac{1}{t_{c}\left(T_{c^{+}}\right)} \\
N_{s}=\lambda \cdot t_{c}\left(T_{c^{+}}\right)
\end{gathered}
$$

Among the variables that can influence the mining costs, the hauling cost can be cited as a high-impact variable. The position of each block inside the deposit has a different weight in relation to its hauling cost. The distance increment is the average distance from the centre of mass of the mined blocks to the plant. Equation
$\mathrm{P}_{\mathrm{m} 0}=$ Mining cost at $\mathrm{T}_{\mathrm{c}^{+}}$capacity (US\$/ton).

the amount of equipment through a relationship derived from Little's law (Equation 21).

22 shows that the distance increment is a function of the production rate and consequently will be proportional to the next area to be extracted (Peurifoy; Ledbetter, 1985).

$$
t_{c}\left(T_{c^{+}}\right)=\int_{0}^{s} \frac{S_{d\left(T_{c^{+}}\right)}}{V} d s
$$

where: $S=$ Segment $S_{d}=$ Segment Size; $V=$ Velocity

Figure 3 shows the distance increments and equipment demand according to the increase in production rate considering a generic iron ore pit. Depending on the production rate, the area to be extracted can have a different size. The distance between the processing plant and the centre of mass of these different areas to be mined was used to measure the increments according to each production rate. The measured values represent the sum of the segments $S_{d}\left(T_{c+}\right)$ used to determine the cycle time $t_{c}\left(T_{c+}\right)$. For lower production volumes, a greater number of trucks are necessary because smallsized equipment is used. Small-sized equipment should be used in greater quantity so that the utility remains within the recommended range of $85 \%$ (Cooper, 1981).

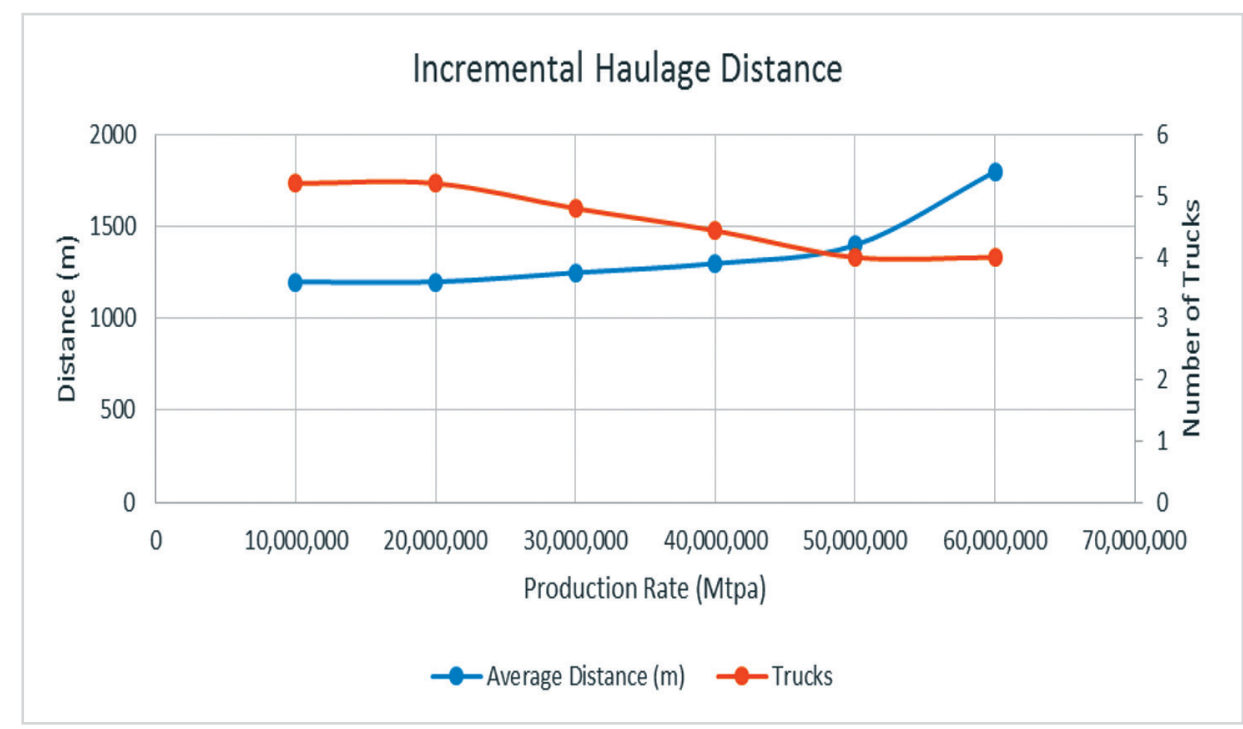


Figure 4 shows the relationship between the mining cost and production rate, and at low production rates, the mining cost per ton is very high. This fact is related to the greater quantity of small-sized equipment because gener-

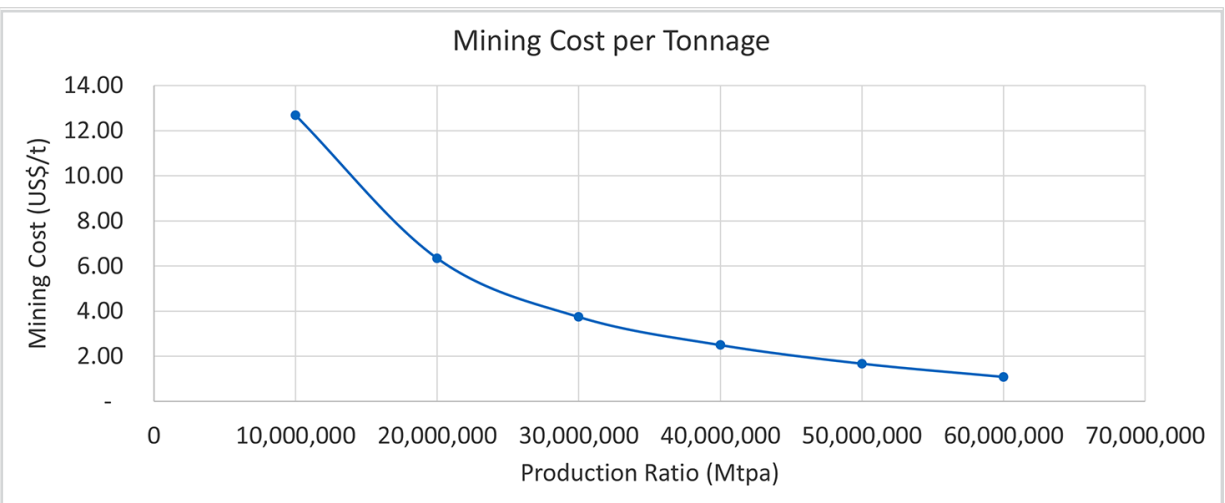

\subsection{Price Simulation}

Equations 2 and 18 use the ore price to determine utility. The ore price and the utility are directly proportional: if the price increases, then the utility also increases. The price simulation performed in this study will influence the expected production rate for the following periods. Iron ore behavior is best modelled by geometric Brownian

motion due to the ability to replicate the volatility and the trend observed in the analysis window (Rahmanpour; Osanloo, 2016). The volatility confers a large number of erratic paths with equivalent probability, according to Cortez et al. (2017). The price simulation can be divided into two parts, namely, deviation and volatility. In the

$$
d S_{t}=\mu S_{t} d_{t}+\sigma S_{t} d W_{t}
$$

where: $S_{t}=$ Simulated solution and $d_{t}=$ Time derivative.

The iron ore prices, obtained from the Index Mundi Institute, were analysed between December 2015 and December 2017 to determine the drift and volatility. Two percent was used for the drift, and $5 \%$ was utilized for the volatility, based on the initial value of US\$70/ton at time zero. A positive value of a $2 \%$ drift was used for a decreasing trend in the long-term simulated prices (Yang et al., 2015). The volatility of $5 \%$ expresses a trend variation near the average, and greater volatility increases the possibility of scattered scenarios. Rahmanpour and Osanloo (Rahmanpour; Osanloo, 2016) do not recommend a long-term extrapolation of the simulation; therefore, the simulated horizon was limited to 10 years.
Figure 5

Price simulation. ally, smaller companies cannot make larger initial investments to reduce the production costs.

Figure 4

Mining cost according to the production rate.

first part of Equation 23, volatility $(\mu)$ is related to the distribution of simulated prices. In the second part of Equation 23 , drift $(\sigma)$ determines the trend of the price simulations: increasing or decreasing. Combining the volatility and drift with the random variable proposed by Wiener $\left(W_{t}\right)$ makes it possible to simulate the price behaviour.

The methodology adopted to simulate the random component of Equation 23 is based on a Monte Carlo simulation. Figure 5 shows the price simulation over the next 10 years with the respective confidence levels of the estimates. The confidence level is a range of values that indicates how precisely a statistic can estimate a parameter.

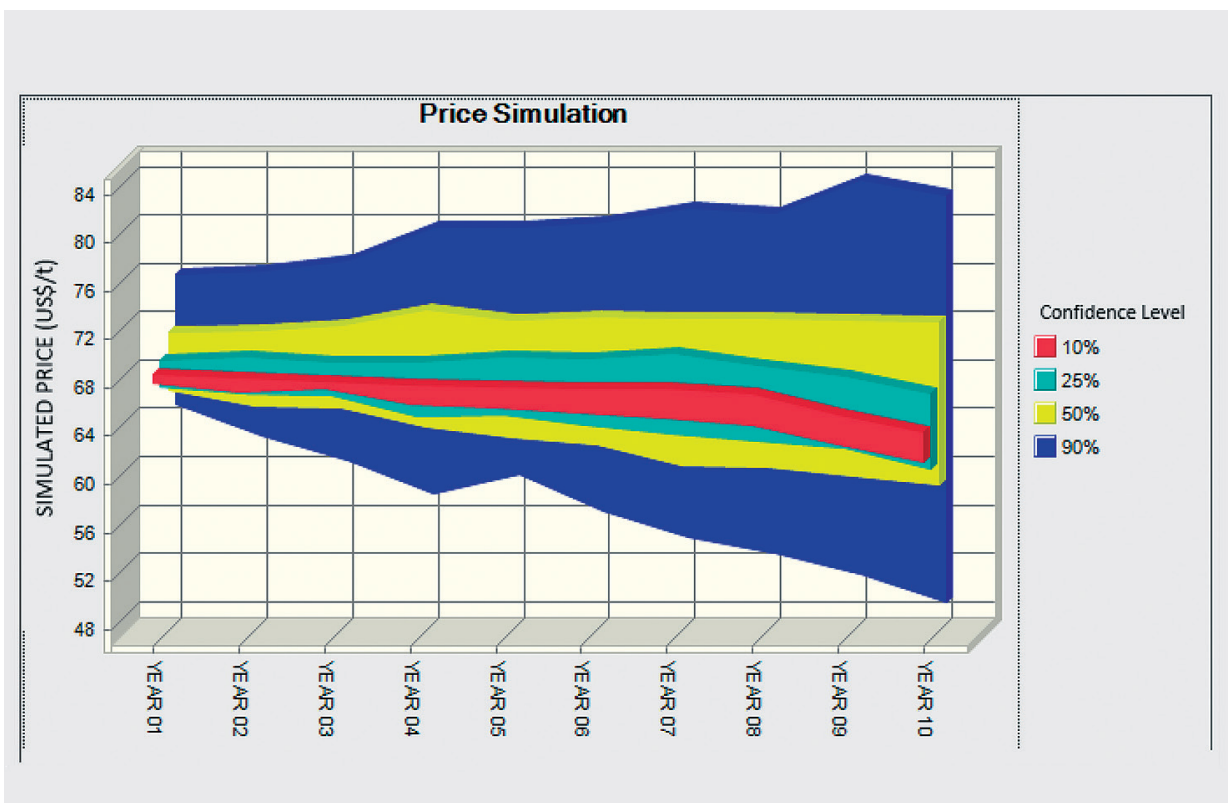




\section{Calculation}

\subsection{Single optimum solution}

The profits that represent the revenue of the processing and mining activities (Equations 2 and 18) are summed to find the optimum production rate. The processing and mining costs are related to the production rate, but it is important to remember that the metallurgical recovery was correlated with the produc- tion rate according to (Rendu, 2014). Equation 24 shows the formulation to be optimized to determine the optimum production rate.

$$
U\left(T_{c^{+}}\right)=Q_{c^{+}} \cdot r\left(T_{c^{+}}\right) \cdot a / c \cdot V-T_{c^{+}} \cdot P_{0}\left(T_{c^{+}}\right)-T_{c^{+}} \cdot P_{m 0}\left(T_{c^{+}}\right)
$$

This topic will demonstrate the optimum production rate considering the selling price of US\$70/ton. The definition of the optimum point of the production rate can be estimated through the graph in
Figure 6 and was confirmed through the first derivative of Equation 24 to be zero (Equation 25). For the scenario presented below, Figure 6 shows the profit for different production rates, and the highest profit

$$
\frac{d U\left(T_{c^{+}}\right)}{d T_{c^{+}}}=0 ; T_{c^{+}}=50.36 \mathrm{Mt}
$$

is in the region between 40 and 60 million tons. The solution to Equation 25 shows that the optimum point corresponds to a production of $50.36 \mathrm{Mt}$, confirming the result from the graph.

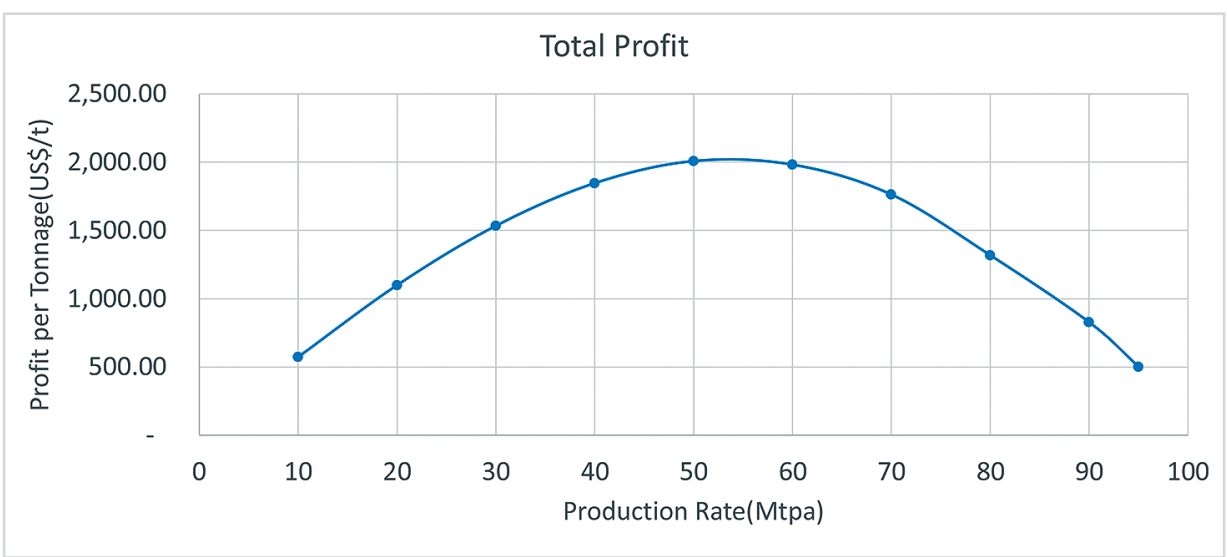

\subsection{Simulated optimum solution}

Item 2.4 (Price Simulation) shows the determination of several simulated price scenarios that apply to the developed formulation change in the utility value to move the optimum point. If the ore price increases, then the utility tends to increase (Hildenbrand, 2014). The concepts of the single optimum solution will be extrapolated to the simulated price scenarios.
Figure 7 Simulated optimum production rate.
The solution determined in Equation 25 is based on a deterministic value, but the utility value is strongly influenced by the price of and total metal contained in ore (Leite; Dimitrakopoulos, 2009). The utility function represented by Equation 24 was also used to optimize scenarios based on simulated prices. For each year of operation, 100 prices were simulated, and each of these 100 prices resulted in an optimum production rate based on the same concept of a single optimum solution (Equation 25). Figure 7 represents the probabilistic distribution of the rates in the 1000 analysed scenarios. The concept of confidence level adopted is similar to a confidence range used on a normal distribution.

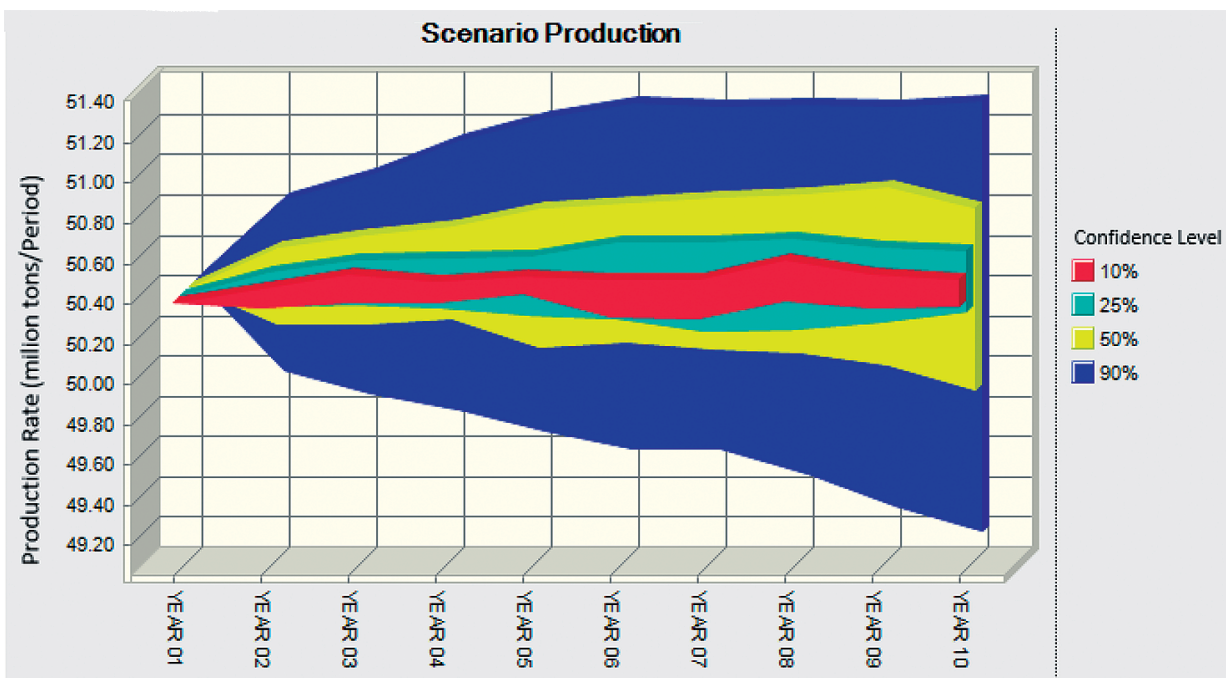




\section{Results}

Before the optimum production rates are discussed, it is important to analyse the formulation behavior in a sensitivity analysis scenario. Figure 8 shows that an increase in the production rate is limited at the upper part. An increase in price above US\$80/ton does not cause a very significant increase in the production

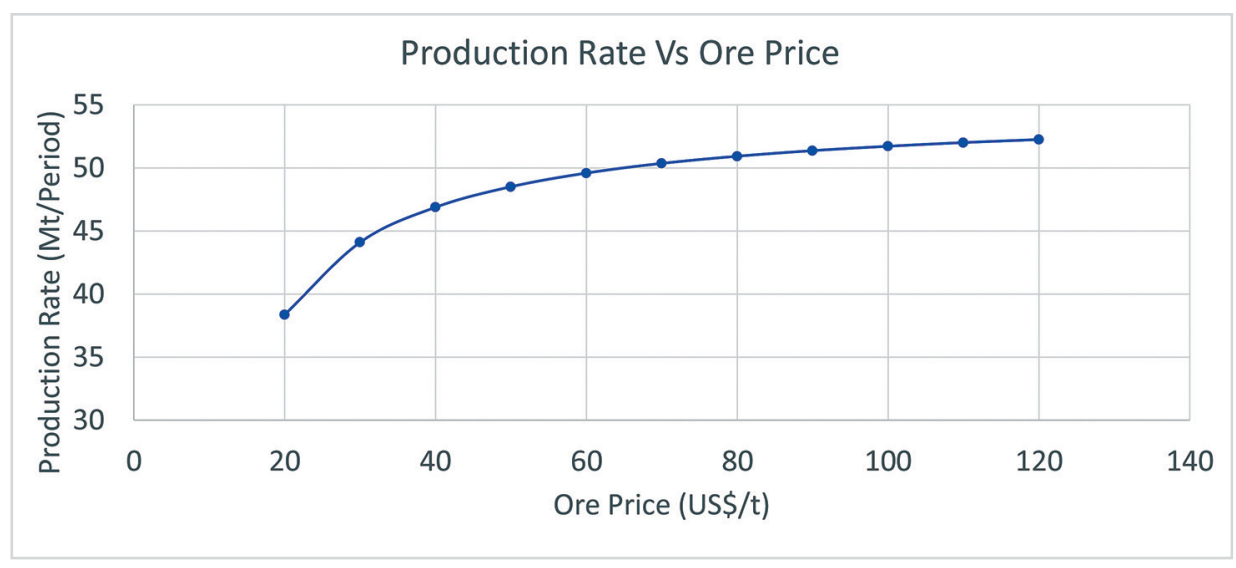

The elasticity concept presented in Equation 1 can be extended to the analysis of Figure 8, where it is possible to conclude that elasticity is not constant for any curves, as predicted theoretically by Tulcanaza (Tulcanaza, 2015). Importantly, the simulated price cannot be lower than the break-even price because simulated scenarios that do not correspond to reality can be generated (Neary, 2001).

A good method to validate the obtained results is verifying the probability of occurrence of the deterministic scenario of US\$70 / ton. For this,

\section{Conclusion}

The proposed formulation to optimize the production rate can represent the economies of scale predicted theoretically, since an increase in production decreases the unit cost. Due to the decrease in the operation efficiency, the ore recovery tends to decrease. The equilibrium point between these systems is represented by the marginal cost of zero, corresponding to the production rate capable of provid-

\section{Acknowledgments}

The authors would like to acknowledge the financial support from Founda- the production rate associated with this price is verified in Figure 8, and in Figure 7, its probability of occurrence can be checked. For a production rate of $50.36 \mathrm{Mt}$, the confidence level is up to $10 \%$ in the first year simulated and increases to approximately $25 \%$ in the last period.

The correlation between price and production demonstrated the need for focus on price simulation (FrancoSepulveda; Campuzano; Pineda, 2017), since a simulation performed with tenuous criteria can lead to a scenario of ing the greatest marginal utility.

The mechanism is easy to adapt to the proposed processing route of the case study, since it consists of adding the cost equations available in literature to the corresponding steps. The metallurgical recovery and increment distance must be analyzed according to the specific characteristics of the operation.

The correlation between produc- tion for Research Support of Minas Gerais State (FAPEMIG) and National Council rate compared to its effect on the lower prices. The behaviour presented is similar to a logarithmic curve in which very high prices will be bounded by an asymptote.

Figure 8

Production sensitivity analysis.

increasing or decreasing production in the wrong direction. The analysis of the drift and volatility variables should obey the needs of each operation and ore type (Rahmanpour and Osanloo, 2016; Yang et al., 2015).

The estimates of mining and processing costs showed the capacity to represent the expected economy of scale for higher production rates. Figure 4 shows that for very small mining rates, the unit cost may vary more with an increase in the mining production rate when compared to the process.

tion rate and selling price was demonstrated, but the upper and lower limits of the simulated price should be observed. A price below the break-even point can make the mine unfeasible, and very high prices do not significantly affect the production rate. The formulation showed the ability to consider the operational and financial parameters not included in Taylor's rules. for Scientific and Technological Development $(\mathrm{CNPq})$ for the research studentship.

\section{References}

ABDEL SABOUR, S. A. Mine size optimization using marginal analysis. Resources Policy, v. 28, n. 3-4, p. 145-151, 2002.

BURGARELLI, Hudson Rodrigues et al. Direct block scheduling under marketing uncertainties. REM, v. 71, n. 2, p. 275-280, 2018.

CAMM, Thomas W. Simplified cost models for prefeasibility mineral evaluations. 
1991.

CAMUS, Juan P. Management of mineral resources: creating value in the mining business. Society for Mining, Metallurgy \& Exploration (SME), 2002.

CAVENDER, B. Determination of the optimum lifetime of a miningproject using discounted cash flow analysis and option pricing techniques. Mining Engineering, n. October, p. 1262-1268, 1992.

CHWIF, L., MEDINA, A. C. Modelagem e simulação de eventos discretos: teoria e aplicações. São Paulo: Bravarte, 2007.

COASE, Ronald H. The nature of the firm. Economica, v. 4, n. 16, p. 386-405, 1937.

COOPER, Robert B. Introduction to Queueing Theory. Second ed. New York, NY: North Holland, 1981. Available in: <www.elsevier.com/locate/comnet\%5Cnhttp:// www.nt.tuwien.ac.at/ltesimulator\%5Cnhttp://fastpass.mit.edu/\%5Cnhttp:// www.ericsson.com/research-blog/internet-of-things/cellular-iot-alphabet-soup/ [03/03/2016\%5Cnhttp://www.urbanfischer.de/journals/aeue\%5Cnhttp://>

DOWD, P. A. Application of dynamic and stochastic programming to optimize cutoff grades and production rates. Mining Technology: IMM Transactions Section A, [s. 1.], v. 85, p. 22-31, 1976.

FRANCO-SEPULVEDA, Giovanni, CAMPUZANO, Carlos, PINEDA, Cindy. NPV risk simulation of an open pit gold mine project under the O'Hara cost model by using GAs. International Journal of Mining Science and Technology, v. 27, n. 3, p. 557-565, 2017.

GROSS, Donald et al. Fundamentals of Queueing Theory. (4th. ed.) John WILEY \& SONS, 2008. Available in: <http://www.zentralblatt-math.org/zmath/en/ search/?an=0949.60002>

HILDENBRAND, Werner. Market demand: theory and empirical evidence. Princeton University Press, 2014.

KAPPAS, George, YEGULALP, Tunce M. An application of closed queueing networks theory in truck-shovel systems. International Journal of Surface Mining, Reclamation and Environment, [s. 1.], v. 5, n. 1, p. 45-51, 1991. Available in: <https://doi.org/10.1080/09208119108944286>

KIZILKALE, Arman C., DIMITRAKOPOULOS, Roussos. Optimizing mining rates under financial uncertainty in global mining complexes. International Journal of Production Economics, v. 158, p. 359-365, 2014. Available in: <http://dx.doi. org/10.1016/j.ijpe.2014.08.009>

LANE, Kenneth F. The economic definition of ore: cut-off grades in theory and practice. Mining Journal Books, 1988.

LEITE, A., DIMITRAKOPOULOS, Roussos. Production scheduling under metal uncertainty; application of stochastic mathematical programming at an open pit copper mine and comparison to conventional scheduling. Publication Series - Australasian Institute of Mining and Metallurgy, p. 27-31, 2009. Available in: <http://ezproxy.unal.edu.co/login?url=http://search.ebscohost.com/login. aspx?direct=true\&db=geh\&AN=2011-019759\&lang=es\&site=eds-live>

LIZOTTE, Y., ELBROND, J. Choice of mine-mill capacities and production schedules using open-ended dynamic-programming. CIM BULLETIN, v. 75, n. 839, p. 154-163, 1982.

MARIZ, Jorge Luiz Valença, PERONI, Rodrigo de Lemos. Estimativa de taxa de produção em fases prematuras de projeto através de dados segmentados por substância mineral, método de lavra e porte dos empreendimentos, p. 423-434, 2018.

NEARY, J. Peter. Of hype and hyperbolas: introducing the new economic geography. Journal of Economic Literature, v. 39, n. 2, p. 536-561, 2001. Available in: <http://www.jstor.org/stable/2698247>

PEURIFOY, Robert Leroy, LEDBETTER, William Burl. Construction planning, equipment, and methods. (4. ed.) New York, NY: McGraw-Hill, 1985.

RAHMANPOUR, M., OSANLOO, M. Determination of value at risk for longterm production planning in open pit mines in the presence of price uncertainty. Journal of the Southern African Institute, [s. 1.], n. November 2015, p. 8-11, 2016. Available in: <http://www.scielo.org.za/scielo.php?script=sci_arttext\&pid=S0038-223X2016000300007>

RENDU, Jean-Michel. An introduction to cut-off grade estimation. (2 nd. Ed.). Society for Mining, Metallurgy \& Exploration (SME), 2014. 
RUNGE, Ian C. Mining economics and strategy. SME, 1998.

SMITH, L. D. The argument for a bare bones base case. CIM bulletin, v. 92, n. 1031, p. $143-150,1999$.

TAPIA CORTEZ, C. A. et al. Alternative techniques for forecasting mineral commodity prices. International Journal of Mining Science and Technology, 2017. Available in: <http://dx.doi.org/10.1016/j.ijmst.2017.09.001>

TAYLOR, H. K. Rates of working of mines-a simple rule of thumb. Institution of Mining and Metallurgy Transactions. Section A. Mining Industry, v. 95, 1986.

TCHA, Moonjoong, WRIGHT, Damione. Determinants of China's import demand for Australia's iron ore. Resources Policy, v. 25, n. 3, p. 143-149, 1999.

TULCANAZA, Edmundo. Avaliação de empreendimentos e recursos minerais. São Paulo, Brasil: Oficina de textos, 2015.

WELLS, Howard M. Optimization of mining engineering design in mineral valuation. Mining Engineering, v. 30, n. 12, p. 1676-1684, 1978.

YANG, Zhijun et al. Geometric Brownian motion model in financial market. Berkeley: University of California, 2015.

Received: 25 June 2018 - Accepted: 06 June 2019.

(c) BY All content of the journal, except where identified, is licensed under a Creative Commons attribution-type BY. 